\title{
Pathophysiology and Diagnosis of Vertebrobasilar Insufficiency: A Review of the Literature
}

\author{
Arlindo Cardoso Lima Neto ${ }^{1,2}$ Roseli Bittar ${ }^{2}$ Gabriel Scarabotolo Gattas ${ }^{3}$ Edson Bor-Seng-Shu ${ }^{4}$ \\ Marcelo de Lima Oliveira ${ }^{4}$ Rafael da Costa Monsanto ${ }^{1}$ Luis Felipe Bittar ${ }^{5}$
}

${ }^{1}$ Department of Otolaryngology, Banco de Olhos de Sorocaba Hospital, Sorocaba, São Paulo, Brazil

${ }^{2}$ Department of Otoneurology, School of Medicine, Universidade de São Paulo (USP), São Paulo, Brazil

${ }^{3}$ Department of Radiology, School of Medicine, USP, São

Paulo, Brazil

${ }^{4}$ Department of Neurology, School of Medicine, USP, São

Paulo, Brazil

${ }^{5}$ Department of Engineering, School of Engineering, USP, São Paulo, Brazil

Address for correspondence Arlindo Cardoso Lima Neto, MD, PhD student, Department of Otolaryngology, Banco de Olhos de Sorocaba Hospital, Praca Nabek Shiroma 210, Sorocaba, São Paulo 18048210 , Brazil (e-mail: arlindo.lima@uol.com.br).

Int Arch Otorhinolaryngol 2017;21:302-307.

\begin{abstract}
Keywords

- vertigo

- ischemia

- stroke

- vertebrobasilar insufficiency

- dizziness

- pathophysiology
\end{abstract}

\section{Introduction}

The term "vertebrobasilar insufficiency" (VBI) is widely used in clinical practice. The first authors to describe its clinical features were Kubic and Adams ${ }^{1}$ in 1946. In 1990, the
National Institute of Neurological Disorders and Stroke (NINDS) defined VBI as a transitory ischemia of the vertebrobasilar circulation, and that definition has remained since then. $^{2}$ received

March 26, 2016

accepted

August 23, 2016

published online

October 26, 2016
DOI https://doi.org/

10.1055/s-0036-1593448. ISSN 1809-9777.
Copyright $(2017$ by Thieme Revinter

Publicações Ltda, Rio de Janeiro, Brazil
License terms

(c) $9 \circledast \$$ 
The ischemia of the vertebrobasilar circulation clinically presents in one of two possible forms: (1) VBI, or (2) stroke related to the posterior circulation. ${ }^{3}$

More than $60 \%$ of patients diagnosed with VBI have at least one episode of dizziness during the course of the disease ${ }^{3}$ and, in our experience, $25 \%$ of the elderly patients complain of imbalance secondary to VBI. ${ }^{4}$ Approximately $20 \%$ of the strokes involve the posterior cerebral circulation. ${ }^{5}$

Even though VBI is easily suspected when the patient presents with neurological impairment associated to the dizziness, cases presenting with mild imbalance could lead to a wrong diagnosis of other causes of vestibular dysfunction. VBI could cause discrete symptoms, which are related to the ischemia of the inner ear circulation, due to atherosclerosis of the vertebrobasilar arterial system. ${ }^{6}$

The objective of this study is to review the literature regarding the clinical features and diagnosis of VBI, highlighting the available diagnostic testing.

\section{Review of the Literature}

\section{Methodology}

We performed a review of the literature study based on a nonsystematic database search. The search was performed from June to September, 2015. Inclusion criteria were original research, review, cross-section, case-control, case report, cohort, and clinical trial articles. Highly-cited articles published in peer-reviewed, high-impact journals referring to the pathophysiology, diagnosis, and available diagnostic testing for VBI were selected for appraisal. We excluded studies published in journals who were not peer-reviewed. Then, we read the selected articles in full and excluded articles that did not comply with our inclusion criteria.

\section{Selected Manuscripts}

Our final study group included 24 studies, 14 of which were original research. Eleven of the studies were published before 2000, and 13 from 2000 to 2013 (- Fig. 1). Regarding the location where the studies were conducted, 12 were American, 8 were European, and 4 were Asian (-Fig. 2). The selected manuscripts that were original research included 12 transversal studies ( 8 cross-sectional, 3 case-controls, 1 series of cases)

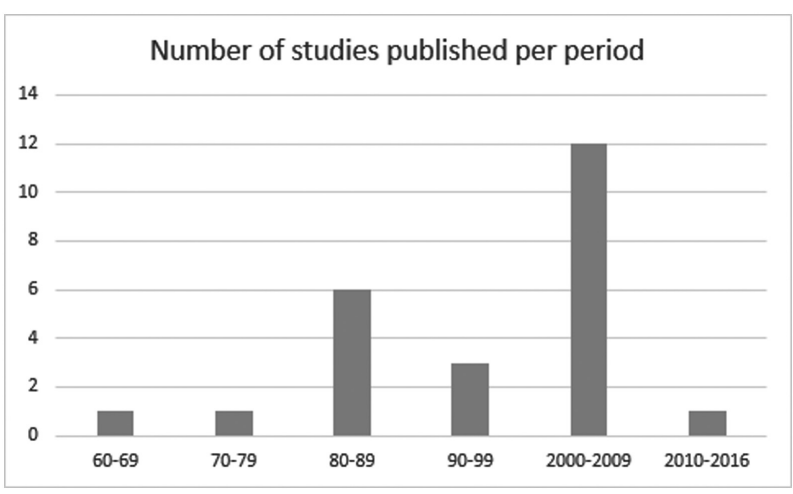

Fig. 1 Number of selected studies, categorized according to the decade of publication.

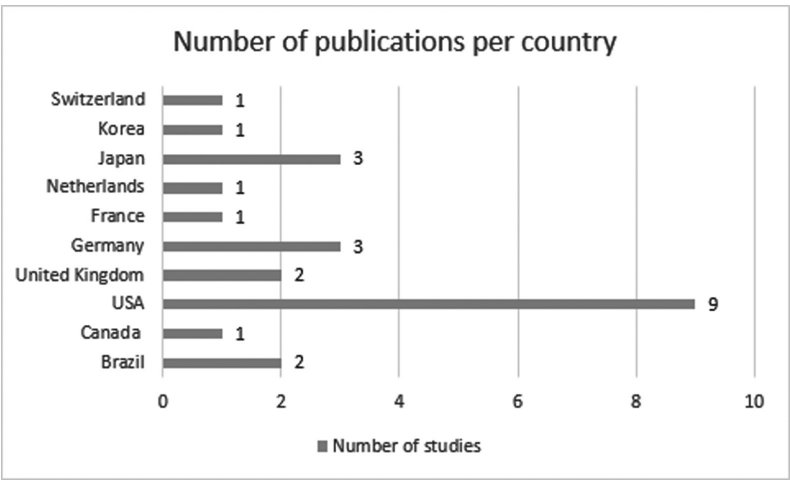

Fig. 2 Number of selected studies categorized according to the country where the article was produced.

and two longitudinal studies (1 prospective and 1 retrospective cohort). The original articles included three descriptions of clinical features of VBI, one demonstrated results of electronystagmography testing, one reported the validity of the vertebral deprivation nystagmus as a diagnostic tool, and 9 compared imaging studies in either controls or patients with VBI (5 studies using magnetic resonance imaging or magnetic resonance angiography, 1 performed angio-tomography in patients with VBI, and 3 reported on Doppler ultrasound results). From the remaining 10 studies, five were reviews, and the other five were anatomic descriptions. Demographic information of these studies are shown in -Table 1.

\section{Discussion}

\section{Causes}

The most frequent cause of the hemodynamic changes that lead to the development of VBI is atherosclerosis. Other common causes are: embolism, atherosclerosis of great vessels, and arterial dissection. Migraine, fibromuscular dysplasia, coagulopathies, and drug abuse are less frequent causes. ${ }^{7}$

Review studies investigating the epidemiology of VBI reported that the prevalence of atherosclerosis and blockage of the vertebrobasilar circulation differ according to the sex and age of the patients. It is more frequently observed in men after the fourth decade of life ${ }^{8}$; arterial hypertension, obesity, and smoking are considered to be the main risk factors. ${ }^{9}$

\section{Clinical Features}

Dizziness, vertigo, headaches, vomit, diplopia, blindness, ataxia, imbalance, and weakness in both sides of the body are the most common symptoms. ${ }^{7-9}$

Some authors advocate that weakness of the lower limbs associated to imbalance and ataxia of the legs, palsy of the oculomotor nerve, and/or oropharynx dysfunction are the most prevalent symptoms of $\mathrm{VBI}^{7}$

Ischemia in the territory of the posterior circulation rarely causes only one symptom at a time through the course of the disease; in most cases, there is an association of different symptoms presenting at the same time. ${ }^{10-12}$

Grad and Baloh $^{3}$, in a cross-section study involving patients with clinical diagnosis of VBI, stated that the 
Table 1 Demographic information of the original research studies selected for appraisal

\begin{tabular}{|c|c|c|c|c|}
\hline Author & Year & Study & Patients & Intervention \\
\hline Grad and Baloh ${ }^{3}$ & 1989 & Cross-sectional & $84-\mathrm{VBI}$ & Electronystagmography \\
\hline $\begin{array}{l}\text { Moubayed } \\
\text { and Saliba }\end{array}$ & 2009 & $\begin{array}{l}\text { Double-blind, } \\
\text { retrospective cohort }\end{array}$ & $\begin{array}{l}61-\text { stenotic or hypoplastic } \\
\text { vertebral artery } \\
72 \text {-controls }\end{array}$ & $\begin{array}{l}\text { Descriptive study - Clinical } \\
\text { analysis of comorbidities }\end{array}$ \\
\hline Gomez et $\mathrm{al}^{6}$ & 1996 & Cross-sectional & $\begin{array}{l}\text { 29-vertebrobasilar ischemic } \\
\text { transient attacks }\end{array}$ & $\begin{array}{l}\text { Descriptive study - Clinical } \\
\text { analysis of the present of isolated } \\
\text { vertigo and vertebrobasilar } \\
\text { insufficiency }\end{array}$ \\
\hline Inui et al ${ }^{14}$ & 1998 & Series of cases & $4-\mathrm{VBI}$ & $\begin{array}{l}\text { Descriptive study - Clinical } \\
\text { features and comorbidities }\end{array}$ \\
\hline Nakagawa et al $^{15}$ & 1998 & Case-Control & $\begin{array}{l}40-\mathrm{VBI} \\
40-\text { Controls }\end{array}$ & MRA \\
\hline Kidwell et al ${ }^{16}$ & 1999 & Case-Control & $\begin{array}{l}\text { 42-transient ischemic attack } \\
20 \text {-complete stroke }\end{array}$ & Diffusion MRI \\
\hline Marx et al ${ }^{17}$ & 2002 & Cohort & $\begin{array}{l}\text { 158-acute brainstem } \\
\text { dysfunction }\end{array}$ & Diffusion MRI \\
\hline Nakagawa et al $^{18}$ & 2000 & Case-control & $\begin{array}{l}\text { 44-VBI } \\
\text { 27-Other peripheral labyrinthine } \\
\text { diseases }\end{array}$ & MRA \\
\hline Kim et al $^{19}$ & 2005 & Cross-sectional & $\begin{array}{l}\text { 182-controls } \\
519 \text {-headache or dizziness } \\
15 \text {-coronary steno-occlusive } \\
\text { disease } \\
26 \text {-old cerebral hemorrhage } \\
121 \text {-anterior circulation infarct } \\
\text { group } \\
72-\text { posterior circulation infarct } \\
\text { group }\end{array}$ & $\begin{array}{l}\text { High-resolution } \\
\text { contrast-enhanced MRA }\end{array}$ \\
\hline Graf et $\mathrm{al}^{20}$ & 2000 & Cross-sectional & $\begin{array}{l}\text { 103-posterior circulation } \\
\text { infarction }\end{array}$ & CT angiography \\
\hline Aaslid et $\mathrm{al}^{22}$ & 1982 & Cross-sectional & 50-controls & Transcranial Doppler Ultrasound \\
\hline Arnolds et $\mathrm{al}^{23}$ & 1986 & Cross-sectional & 51-controls & Transcranial Doppler Ultrasound \\
\hline Tegeler et $\mathrm{al}^{24}$ & 2013 & Cross-sectional & 364-controls & Transcranial Doppler Ultrasound \\
\hline Bottino et $\mathrm{al}^{26}$ & 2000 & Cross-sectional & $\begin{array}{l}\text { 21-VBI and positive vertebroba- } \\
\text { silar deprivation maneuver }\end{array}$ & $\begin{array}{l}\text { Diagnosis of VBI through the } \\
\text { vertebrobasilar deprivation } \\
\text { nystagmus }\end{array}$ \\
\hline Total & $1982-2013$ & $\begin{array}{l}8 \text { Cross-sectional } \\
2 \text { Cohort } \\
3 \text { Case-control } \\
1 \text { Series of cases }\end{array}$ & $\begin{array}{l}\text { 779-VBI, transient ischemia, or } \\
\text { stroke (not used as controls) } \\
\text { 1469-controls }\end{array}$ & - \\
\hline
\end{tabular}

most frequent symptoms in this population were: visual symptoms (diplopia, visual hallucinations, deficits in the visual field, and blindness); drop attacks (sudden falls secondary to loss of tonus in the lower limbs, without loss of consciousness); and muscular incoordination and weakness. Mental confusion, headaches, hearing loss, paresthesia, dysarthria, and tinnitus are less frequent symptoms. Among their reported cases, almost 20\% of the patients presented with peripheral nystagmus, and none showed nystagmus, suggesting a central origin. The symptoms usually started within a period that varied from 3 weeks to 3 years prior to the first consultation.
Isolated attacks of dizziness, or even the chronic imbalance that lasts more than 3 weeks are rarely associated with VBI, and are most commonly observed in diabetic patients. ${ }^{7}$

Descriptive studies published by Gomez ${ }^{6}$ and Grad and Baloh $^{3}$ involving only patients with VBI (confirmed by impairment on the vertebrobasilar blood flow in the angiography) stated that the dizziness complaints of these patients could begin within a time frame ranging from 4 weeks to 4 years, before neurologic signs are clinically observed. Furthermore, a review study comparing diagnostic testing for early diagnosis of occlusions in the posterior cerebral circulation reported angiography to be the most reliable test for this purpose. ${ }^{13}$ 
Gomez ${ }^{6}$, in a cross-section descriptive study, suggested that some characteristics of dizziness might be typical in VBI patients: sudden dizziness spells, lasting 30 seconds to 15 minutes, starting after abruptly standing up or turning the head; also, it has no association with positional complaints, hearing loss, tinnitus, and aural fullness. An ongoing research conducted by our group, so far, failed to observe any specific characteristic of the dizziness in patients diagnosed with VBI. Nonetheless, the incidence of changes in other cranial nerves (visual complaints, by example) seems to be higher. Furthermore, we observed a trend in the diagnosis of VBI in patients with one or more of the following conditions: (1) risk factors for cerebrovascular disease; (2) frequent episodes of vertigo that last minutes, waning within days or weeks; and/or (3) absence of hearing loss or tinnitus.

Other possible symptoms of the disease can be secondary to the lateral medullary syndrome, also known as Wallenberg syndrome. This entity is characterized by a stroke in the vertebral artery or PICA irrigation territories in the brainstem. Symptoms include difficulties swallowing, hoarseness, dizziness, nausea and vomiting, nystagmus, and imbalance and gait incoordination. ${ }^{7}$

\section{Pathophysiology of the VBI and the Vestibular Symptoms}

Several anatomic studies reported the complexity of the irrigation pattern of the vestibular system, and suggested that fact to play a major role in the pathophysiologic mechanism of the VBI presenting with labyrinthic symptoms. ${ }^{7-9}$ The vestibular system is supplied by: (1) very small penetrating vessels coming from the basilar artery, supplying the vestibular nuclei; and (2) the internal auditory artery (IAA), originated either from (a) the anterior-inferior cerebellar artery (80-85\%); or (b) a vascular loop from the posterior-inferior cerebellar artery (PICA), which is a branch of the vertebral artery (15\%). The PICA is a terminal vessel with very few collateral branches. The IAA irrigates the cochleovestibular nerve, the cochlea, and the posterior labyrinth. ${ }^{3,6}$ Inui et al ${ }^{14}$ described in a report of four cases how the AICA emerge from the basilar artery, and the PICA from one of the vertebral arteries in $56 \%$ of the cases.

Considering that the labyrinthine branches are smaller and receive less collateral irrigation, it is possible that the labyrinth should be more affected by atherosclerotic blockage of the vertebrobasilar arterial system. On the other hand, the cochlea receives collateral irrigation from the carotid artery, supplying adjacent portions of the petrous bone. This particular feature prevents the cochlea from suffering ischemic symptoms in the case of a vascular insufficiency. ${ }^{6}$

Moubayed and Saliba, ${ }^{5}$ in a double-blind retrospective cohort, studied the prevalence of positional dizziness and imbalance, plus clinical and electronystagmography findings in two groups: one with changes in the vertebral arteries in magnetic resonance angiography (stenotic or hypoplastic vertebral arteries) and one without any changes. The authors observed no differences between the two groups. These results suggest that the clinical symptoms are triggered by occlusion or obstruction in smaller vessels, in more distal regions.
Isolated episodes of vertigo could arise from transient ischemia of the vestibular labyrinth, due to the characteristics of its terminal circulation without collateral vessels. ${ }^{3}$ The fact that the posterior labyrinth integrates information bilaterally in a more active way than the cochlea also explains why VBI causes more vestibular than cochlear symptoms. Thus, the vestibular system could be more sensitive in detecting differences in the action potential secondary to ischemia. ${ }^{6}$

The ischemia could affect both peripheral and central structures of the vestibular system. Moubayed and Saliba ${ }^{5}$ describe two mechanisms through which the ischemic episodes could cause isolated dizziness spells: (1) decrease in the blood flow to the vestibular nuclei or to the root of the entrance zone of the vestibulo-cochlear nerve; and (2) direct ischemia of the labyrinth.

\section{Diagnosis of VBI by Neuroimaging}

The patients with a suspected diagnosis of transient ischemic attacks or vertebrobasilar strokes should undergo neuroimaging tests. Even though arteriography is considered to be the most important exam for this purpose, the risks of performing this test in patients with VBI should be taken in consideration. Many patients choose not to take this test after reading the risks of the procedure in the informed consent terms. The main complications of the arteriography are: local complications of the arterial catheters; regional low blood flow; and stroke. ${ }^{15}$

The magnetic resonance angiography (MRA) has been widely studied and it is considered to be a good method to identify and localize any occlusions and stenosis in both neck and intracranial great vessels. ${ }^{15-17}$ Nakagawa et al ${ }^{15,18}$ compared patients with VBI to non-diseased controls and patients with other peripheral labyrinthine diseases and reported some findings to be characteristic in patients VBI: focal atherosclerosis decreasing the lumen of the basilar artery (mainly when close to the exit of the AICA), and diffuse narrowing in the origin of the vertebral artery with decreased distal blood flow. In one of those studies, Nakagawa et al ${ }^{18}$ reported that stenosis of the basilar artery was a significant finding among patients with the diagnosis of VBI when compared with age-matched controls. Nonetheless, the surprisingly high incidence of anomalies found by the authors (30\%) with high levels of statistical significance $(p=0.003)$ may raise concerns about the inclusion and exclusion criteria of the patient selection in the study.

Moubayed and Saliba ${ }^{5}$ evaluated patients with positional dizziness and imbalance regarding the morphology of the vertebral arteries, risk factors for stroke involving the posterior circulation, and evolution of the symptoms over time in patients with VBI compared with controls. They concluded that $85.7 \%$ of the patients with dizziness and at least 3 risk factors for stroke have morphologic abnormalities in the vertebral arteries.

Kim et al $^{19}$ dedicated a study to evaluating the prevalence of occlusion and stenosis in the proximal segments of the vertebral arteries, comparing the results with changes of the distal segments. The authors performed magnetic resonance arteriography in 935 patients divided in 6 different groups: (1) asymptomatic volunteers; (2) lesser symptoms, such as: 
headaches, tinnitus, seizures, movement disorders, anxiety, dementia, traumatic head injuries, or symptoms of transitory ischemia; (3) patients with occlusion or stenosis of the coronary arteries; (4) patients with previous intracranial bleeding; (5) patients with stroke of the anterior circulation; and (6) patients with stroke related to the posterior circulation. The prevalence of stenosis increased gradually accordingly to the severity of the disease, and the results were statistically significant $(p<0.0001$ for every performed comparison). The authors also consider the proximal region of the vertebral arteries to be the place with a higher prevalence of occlusion of the posterior circulation. They also state that more studies focusing on understanding the natural history of these lesions and their evolution over time are still needed.

A small number of publications dedicated on evaluating posterior circulation; however, studies in healthy patients points toward angio-tomography and MRA to reach similar sensibility and specificity levels, especially when studying the basilar artery. ${ }^{20}$ The advantage of the angio-tomography is that it provides less false-positive results, due to the smaller influence of the slower blood flow in some narrow portions of the posterior circulation on the results. Other studies in healthy subjects reported the sensibility of the magnetic resonance angiography, angio-tomography, and transcranial Doppler to be $93.9 \%, 100 \%$, and $70.2 \%$, respectively, while the specificity rate was $94.8 \%, 95.2 \%$, and $97.7 \%{ }^{21}$

The transcranial Doppler is a cheap, pain-free, and noninvasive test, which is capable of measuring the speed and direction of the blood flow from the proximal areas of the great intracranial arteries. The first clinical application of this exam was described in $1982 .^{22}$ In a report named "The vascular diagnosis guidelines," published by the American Academy of Neurology, the authors report the Doppler as a high sensitivity (50-80\%) and high specificity (80-96\%) exam. ${ }^{13}$

Another important piece of information given by the Doppler is the pulsatility index (PI), which is the relation between the measured speed of the blood flow during the systolic pulse and the final diastolic pulse. Studies in the general healthy population demonstrated that the lower this relation, the greater the resistance of the adjacent microvasculature. This index is highly predictive of early hemodynamic intracranial changes. ${ }^{23}$

It is known that the speed of the intracranial arterial blood flow decreases and PI increases in older male patients, even in those without any cerebrovascular diseases. The opposite phenomenon is observed in female patients: the speed increases and PI decreases. It has also been demonstrated that there were no differences among different ethnic groups, regarding the blood flow speed and PI of the posterior circulation. ${ }^{24}$ Such facts should be taken into consideration when evaluating the results of this exam in patients with different sex and ethnicity.

\section{Diagnosis of VBI through the Vertebrobasilar Deprivation Nystagmus}

The vertebrobasilar deprivation nystagmus, according to Caussé et $\mathrm{al}^{25}$, is the nystagmus obtained using an extension and rotation of the neck for three minutes, when every other possible cause of nystagmus has been discarded. This nystagmus would occur because of a decrease in the blood flow in the opposite vertebral artery because of the head rotation. Moubayed and Saliba ${ }^{5}$ reported the physiopathology of this event to be secondary to the depolarization of the ciliated cells, caused by an acute onset of ischemia, generating a nystagmus. However, in a late phase of the ischemic injury, the membrane of the axons become incapable of excitation, resulting in a hypofunction of these cells. Nonetheless, this explanation is controversial, because if the basilar artery has a normal blood flow, there would be no reason for decreased perfusion of the terminal circulation. Inui et $\mathrm{al}^{14}$ reported the case of a patient showing nystagmus when turning the head to the left side, and exams pointed to an occlusion of the ipsilateral vertebral artery. This suggests a decrease in the blood flow on the right vertebral artery; the decreased blood flow in the occluded left artery was not enough to supply the basilar artery, generating the nystagmus.

Bottino $^{26}$ studied patient with clinical symptoms of VBI and compared with patients without any kind of disease. He observed the presence of NPVB in $43.4 \%$ of the diseased patients versus $13.3 \%$ in the control group. In the same study, the authors also report the results of Doppler of the carotid and describe vertebral arteries in 21 patients with nystagmus secondary to vertebrobasilar deprivation. The sensitivity of the exam was around $19 \%$. The authors conclude that using this clinical maneuver is a cheap, sensitive, and safe procedure to diagnose VBI. ${ }^{26}$

\section{Limitations}

This study has several limitations. The small number of good randomized, double-blind, clinical trials, and well-designed case-control and cohort studies limits interpretation and validity of some of the results. The high variability of measures and outcomes among the studies about the same diagnostic testing, anatomic feature, or patients selected as control groups, were also limiting factors in our analysis. Nonetheless, we were able to provide a meaningful review including several aspects of the pathophysiology and available diagnostic testing for VBI.

\section{Final Comments}

VBI should be suspected in patients presenting with risk factors for ischemia and vestibular symptoms. Each diagnostic test offers different pros and cons, thus, each patient should be treated individually to avoid possible sequels.

\section{References}

1 Kubik CS, Adams RD. Occlusion of the basilar artery; a clinical and pathological study. Brain 1946;69(2):73-121

2 Special report from the National Institute of Neurological Disorders and Stroke. Classification of cerebrovascular diseases III. Stroke 1990;21(4):637-676

3 Grad A, Baloh RW. Vertigo of vascular origin: Clinical and electronystagmographic features in 84 cases. Arch Neurol 1989; 46:281-284 
4 Simoceli L, Bittar RMS, Bottino MA, Bento RF. Perfil diagnóstico do idoso portador de desequilíbrio corporal: resultados preliminares. Rev Bras Otorrinolaringol 2003;69:772-777

5 Moubayed SP, Saliba I. Vertebrobasilar insufficiency presenting as isolated positional vertigo or dizziness: a double-blind retrospective cohort study. Laryngoscope 2009;119(10): 2071-2076

6 Gomez CR, Cruz-Flores S, Malkoff MD, Sauer CM, Burch CM. Isolated vertigo as a manifestation of vertebrobasilar ischemia. Neurology 1996;47(1):94-97

7 Savitz SI, Caplan LR. Vertebrobasilar disease. N Engl J Med 2005; 352(25):2618-2626

8 Caplan LR, Gorelick PB, Hier DB. Race, sex and occlusive cerebrovascular disease: a review. Stroke 1986;17(4):648-655

9 Caplan LR. Intracranial branch atheromatous disease: a neglected, understudied, and underused concept. Neurology 1989;39(9): 1246-1250

10 Caplan L. Posterior circulation ischemia: then, now, and tomorrow. The Thomas Willis Lecture-2000. Stroke 2000;31(8):2011-2023

11 Bradshaw P, McQuaid P. The syndrome of vertebrobasilar insufficiency. Q J Med 1963;32:279-296

12 Bruyn GW. Vertigo and vertebrobasilar insufficiency. A critical comment. Acta Otolaryngol Suppl 1988;460:128-134

13 Sloan MA, Alexandrov AV, Tegeler $\mathrm{CH}$, et al. Therapeutics and Technology Assessment Subcommittee of the American Academy of Neurology. Assessment: transcranial Doppler ultrasonography: report of the Therapeutics and Technology Assessment Subcommittee of the American Academy of Neurology. Neurology 2004; 62(9):1468-1481

14 Inui $\mathrm{H}$, Yoneyama $\mathrm{K}$, Kitaoku $\mathrm{Y}$, et al. Four cases of vertebrobasilar insufficiency. Acta Otolaryngol Suppl 1998; 533:46-50

15 Nakagawa T, Yamane H, Nakai Y, Shigeta T, Takashima T. Evaluation of the vertebrobasilar artery system by magnetic resonance angiography in the diagnosis of vertebrobasilar insufficiency. Acta Otolaryngol Suppl 1998;538:54-57
16 Kidwell CS, Alger JR, Di Salle F, et al. Diffusion MRI in patients with transient ischemic attacks. Stroke 1999;30(6):1174-1180

17 Marx JJ, Mika-Gruettner A, Thoemke F, et al. Diffusion weighted magnetic resonance imaging in the diagnosis of reversible ischaemic deficits of the brainstem. J Neurol Neurosurg Psychiatry 2002; 72(5):572-575

18 Nakagawa T, Shigeta T, Takashima T, Tomiyama K. Magnetic resonance angiography evaluation of basilar artery stenosis in patients with vertebrobasilar insufficiency. Eur Arch Otorhinolaryngol 2000;257(8):409-411

19 Kim SH, Lee JS, Kwon OK, Han MK, Kim JH. Prevalence study of proximal vertebral artery stenosis using high-resolution contrastenhanced magnetic resonance angiography. Acta Radiol 2005; 46(3):314-321

20 Graf J, Skutta B, Kuhn FP, Ferbert A. Computed tomographic angiography findings in 103 patients following vascular events in the posterior circulation: potential and clinical relevance. J Neurol 2000;247(10):760-766

21 Khan S, Cloud GC, Kerry S, Markus HS. Imaging of vertebral artery stenosis: a systematic review. J Neurol Neurosurg Psychiatry 2007; 78(11):1218-1225

22 Aaslid R, Markwalder TM, Nornes H. Noninvasive transcranial Doppler ultrasound recording of flow velocity in basal cerebral arteries. J Neurosurg 1982;57(6):769-774

23 Arnolds BJ, von Reutern GM. Transcranial Doppler sonography. Examination technique and normal reference values. Ultrasound Med Biol 1986;12(2):115-123

24 Tegeler $\mathrm{CH}$, Crutchfield K, Katsnelson M, et al. Transcranial Doppler velocities in a large, healthy population. J Neuroimaging 2013; 23(3):466-472

25 Causse JB, Conraux C, Causse J. [Vertebral-basilar artery insufficiency nystagmus (author's transl)]. Ann Otolaryngol Chir Cervicofac 1978;95(3):225-234

26 Bottino MA, Molnar LY, Bittar RSM, Venosa AR, Morais FV. Nistagmo de Privação Vértebro-Basilar e Doppler no Diagnóstico de Insuficiência Vértebro-Basilar. Rev Bras Otorrinolaringol 2000;66:251-254 